\title{
Eldesalojo por ocupación precaria a la luz del Cuarto Pleno Casatorio Civil ${ }^{(* *)}$
}

\section{The eviction due to precarious occupation in the light of the Fourth Civil Cassation Plenaries}

\begin{abstract}
Resumen: En el presente artículo el autor no presenta la situación de los precarios y los procesos de desalojos donde se ven involucrados. Asimismo, nos cuenta acerca de la situación engorrosa y la nula seguridad jurídica que existía acerca del tema antes de la emisión del Cuarto Pleno Casatorio Civil. A partir del Pleno, señala el autor, se dieron reglas para identificar este problema y llegar a conclusiones uniformes por parte de los jueces, lo que representa un avance en la predictibilidad de las resoluciones judiciales sobre el desalojo por ocupación precaria.
\end{abstract}

Palabras Clave: Poseedor - Precario - Derecho a la Posesión - Proceso de Desalojo - Predictibilidad - Pleno Casatorio

\begin{abstract}
In this article the author show us the situation of the precarious along the eviction process where they are involved. Likewise, he tell us regarding the cumbersome situation and the null legal certainty that existed about this theme before the emission of the Fourth Civil Cassation Plenaries. After the Plenaries, the author points, were given rules to identify this matter and reach uniforms conclusions by judges, which represents an advance in the predictability of the judicial decisions about the eviction by precarious occupation.
\end{abstract}

Keywords: Holder - Precarious - Right to the Possession - Eviction Process - Predictability - Cassation Plenaries

$\left(^{*}\right.$ Abogado por la Pontificia Universidad Católica del Perú. Profesor de Derecho Civil en la Pontificia Universidad Católica del Perú. Socio de Jorge Avendaño Abogados. Miembro extraordinario de la Asociación IUS ET VERITAS. Correo electrónico: luisfelipe.delrisco@eja.com.pe

$\left(^{* *}\right.$ El autor contó con la colaboración de Luis Diego Vargas Sequeiros, practicante del Estudio Jorge Avendaño Abogados, asistente de docencia del curso de Derechos Reales, miembro de la Asociación IUS ET VERITAS, estudiante de la Facultad de Derecho de la Pontificia Universidad Católica del Perú; y, Christian Fabrizio Basaldúa Chincha, practicante del Estudio Jorge Avendaño Abogados, estudiante de la Facultad de Derecho de la Pontificia Universidad Católica del Perú.

$\left.{ }^{(* *}\right)$ Nota del Editor: el presente artículo fue recibido el 03 de octubre de 2016 y su publicación fue aprobada el 22 de noviembre del mismo año. 


\section{El desalojo por ocupación precaria a la luz del Cuarto Pleno Casatorio Civil The eviction due to precarious occupation in the light of the Fourth Civil Cassation Plenaries}

\section{Introducción}

Partiendo de una visión tradicional del proceso de desalojo por ocupación precaria, el poseedor siempre ha sido considerado como la parte débil de la relación jurídica y, por tanto, merecedor de especial cuidado y protección. El poderoso reclamante contra el ocupante endeble. Así, se entendía que el primero podía abusar de su derecho a desalojar al segundo, quien injustamente tendría que retirarse del inmueble en el que probablemente había vivido muchos años y buscar, con mucha dificultad, otro lugar donde instalarse.

La imagen mental inmediata es la de un titular inescrupuloso contra un ocupante desvalido. Algún principio de justicia ordena entonces que el derecho a poseer del demandante sea aplazado, que el remedio para proteger la titularidad no sea aplicado de inmediato o que finalmente la falta de restitución en esas circunstancias no revista de mayor importancia para el sistema jurídico. Se prefiere, en buena cuenta, mantener el status quo posesorio a resolver la urgencia de que el predio retorne a quien prueba tener una titularidad sobre él.

El tema que nos ocupa se trata de un esfuerzo judicial para darle un enfoque distinto al problema del desalojo por ocupación precaria. Se brinda una respuesta diferente a la pregunta sobre quién debe ser sujeto de protección especial en este proceso y, en definitiva, cuál debe ser la aspiración legal de nuestro ordenamiento: ¿debe ofrecerse una tutela rápida y eficaz a quien tiene derecho a la posesión sobre el predio o debe cautelarse la posesión actual hasta que esta sea vencida en largos y complejos procesos judiciales que diluciden todo el fenómeno posesorio y los elementos asociados a él? En otras palabras, ¿debe promoverse o limitarse el proceso de desalojo?

El Cuarto Pleno Casatorio Civil de fecha 14 de agosto de 2013 ha renovado la visión judicial de este problema, prefiriendo otorgar una tutela urgente de la titularidad que procura el retorno del bien. Con esta nueva lectura jurisprudencial se permite que a través de un examen preliminar de la controversia, se haga efectivo el derecho a la posesión, sin perjuicio de que luego pueda revisarse la solución tomada en un proceso más largo. Sin duda significa un importante voto de confianza al proceso de desalojo en nuestro sistema.
En su afán de uniformizar la figura del precario en el ordenamiento peruano y evitar mayores discusiones al respecto, el Cuarto Pleno Casatorio Civil ha establecido un mecanismo de protección que pretende ser rápido y efectivo para defender el derecho del propietario, del administrador o de todo aquel que se considere que tiene derecho a la restitución de un predio (titulares en general), eliminando cualquier traba en el camino que pudiese prolongar innecesariamente el remedio legal de la restitución.

En las siguientes líneas describiremos brevemente el panorama anterior al Cuarto Pleno Casatorio Civil, tanto en la jurisprudencia como en la doctrina nacional. Luego repasaremos las reglas fijadas por el precedente judicial, analizando cada una de ellas y si estas guardan relación con la figura del precario recogida en el artículo 911 del Código Civil.

\section{El panorama anterior al Cuarto Pleno Casatorio Civil}

\subsection{En la jurisprudencia}

¿Cuál era la problemática que pretendía ser resuelta a través del Cuarto Pleno Casatorio? ¿Cuál era la situación que ameritó que los jueces de la Corte Suprema se reunieran para establecer un precedente vinculante en esta materia? ¿Era realmente necesario este pronunciamiento?

El panorama anterior al pleno era muy desalentador. Bastaba con que el demandado alegara alguna causal que no pudiese ser analizada en un proceso tramitado en la vía sumarísima (el desalojo), para que los jueces desestimaran la demanda y dictaran una sentencia inhibitoria. Bajo este argumento, declaraban improcedente el desalojo y se abstenían de pronunciarse sobre las cuestiones de fondo, las cuales según ellos 


\section{Luis Felipe Del Risco}

debían ser abordadas en otro proceso más largo, con mayor amplitud de debate y prueba.

De esta manera, el desalojo fue perdiendo vigencia como instrumento procesal de recuperación urgente y pasó a un segundo plano, siendo fácilmente burlado por la mera alegación del demandado. Si se invocaba alguna causal de nulidad en el título del demandante, si se aducía la prescripción adquisitiva del bien ocupado o si se planteaba la discusión sobre la propiedad de las construcciones levantadas en el predio por parte del poseedor, el desalojo simplemente no prosperaba, pues se tenía que dilucidar previamente, en otros procesos más largos, la nulidad del acto jurídico, la prescripción adquisitiva de dominio o la declaración de propiedad de las edificaciones, respectivamente.

Se postergaba pues la restitución solicitada por el demandante y no podía brindarse tutela hasta que no se definieran, en un proceso de conocimiento, las materias propuestas por el demandado como parte de su defensa. La complejidad de la discusión hacía que la vía sumarísima del desalojo se desbordara y no fuera útil para resolver la controversia. Al menos así se entendía.

¿Qué ocurría con la solución descrita? Precisamente el problema no era resuelto. El titular de la posesión se veía privado de su derecho y el desalojo no podía ser activado para cumplir con su finalidad, ya que la controversia estaba compuesta por otros factores que debían ser resueltos con antelación. No había pues un marco jurídico claro donde pudiera proponerse el desalojo sin que este sea desplazado por una discusión principal. Esto evidentemente era gravísimo y se prestaba al abuso de los operadores jurídicos.

Nótese que por más que el desalojo se tramite en la vía sumarísima y que en él no haya posibilidad de ahondar en cuestiones complejas que sí podrían ser tratadas en un proceso de conocimiento, el juez nunca debe dejar de impartir justicia y para tal efecto debe formarse un nivel de convicción suficiente que le permita sentenciar de manera que pueda brindar una tutela efectiva al derecho a la posesión.
Recordemos, además, que lo que resuelve un juez dentro de un proceso de desalojo no impide iniciar posteriormente un proceso más largo para analizar los aspectos complejos del caso. Por ejemplo, si se produce una situación de precariedad por una discusión sobre la resolución contractual del título que habilitaba la posesión, el juez debe formarse un nivel de convicción suficiente que le permita decidir sobre el decaimiento del título, sin pronunciarse ni declarar nada sobre la resolución contractual. Este tema no se cierra con la sentencia que resuelve el desalojo, sino que puede ser discutido a través de un proceso de mayor latitud.

No obstante lo expuesto, nuestra judicatura prefería lo contrario; es decir, poner en lista de espera al proceso de desalojo, bajo el argumento de que la raíz u origen de la precaridad debía ventilarse primero en procesos judiciales más extensos. De esta forma, un juicio que debió entrar por la sala de emergencia del hospital, terminó recibiendo una cita médica con un plazo incierto de atención, exponiendo al paciente a severos perjuicios.

Recuérdese que antes del Cuarto Pleno Casatorio, la Corte Suprema declaraba improcedente demandas de desalojo porque había asuntos pendientes por definir previos a la tutela urgente de restitución. Por ejemplo, en la Casación No. 1040-2003-Lima se indicó que el demandante no había probado ser propietario de la edificación, sino solo del suelo, por lo que se tenía que determinar en otro proceso judicial más largo la propiedad de lo edificado(1). De manera muy similar ocurre con la Casación No. 3044-2006-Lima ${ }^{(2)}$.

(1) Sobre el particular, en el cuarto considerando de la Casación No. 1043-2003-Lima se señaló lo siguiente: “(...) en el decurso del proceso el demandante no ha probado ser propietario de la edificación, y su título solo está referido al suelo, por lo que, de lo expuesto en el considerando precedente, previamente deberá definirse la situación de propiedad de lo edificado, y si este se produjo de buena o mala fe, con las consecuencias jurídicas correspondientes determinadas en el Código Civil". 


\section{El desalojo por ocupación precaria a la luz del Cuarto Pleno Casatorio Civil The eviction due to precarious occupation in the light of the Fourth Civil Cassation Plenaries}

En esta misma línea, en la Casación No. 3780-2000-Callao se señala que, dada la naturaleza del proceso de desalojo, no se puede resolver en su interior la discrepancia vinculada a si un contrato quedó efectivamente resuelto o no. Para determinar si realmente el título ha fenecido o no, debía analizarse la resolución contractual en un proceso más lato(3).

Del mismo modo, podemos encontrar jurisprudencia contradictoria para casos similares. Así, la precariedad surgida por la venta del bien arrendado en un alquiler no inscrito, tenía distintas perspectivas en sede judicial, una que cierra el camino para el desalojo (Casación No. 2540-1999-Lima(4) y otra que lo permite (Casación No. 1875-2008-Cañete $\left.{ }^{(5)}\right)$.

En fin, la disparidad de criterios judiciales sobre el asunto era alarmante. No había predictibilidad y, por ende, tampoco seguridad jurídica. Lejos de proveer una solución adecuada a los particulares, estas decisiones judiciales generaban serios perjuicios para el derecho a la posesión, pues no solo no resolvían el problema (definir a quién le corresponde la posesión del bien de acuerdo a un estudio sumario de la controversia), sino que establecían que necesariamente debía atravesarse una ruta más larga y frustrante para poder hacerlo efectivo, lo que implicaba, desde luego, mayores costos de tiempo y dinero.

\subsection{En doctrina}

El artículo 911 del Código Civil establece que "la posesión precaria es la que se ejerce sin título alguno o cuando el que se tenía ha fenecido". Esta definición legal, aunque sencilla en su formulación, ha generado un extenso debate en doctrina nacional.

Un sector considera que el precario es una especie de poseedor inmediato, en tanto hay una relación de precariedad entre el concedente y el precario basada en un título social, que le permite a este último poseer el bien por mera tolerancia o liberalidad. Esta postura asocia al precario del artículo 911 del Código Civil con la figura del precario romano, que hacía referencia a una persona a la que se le permitía ocupar un inmueble por un tiempo

(2) Al respecto, en el cuarto considerando de la Casación No. 3044-2006-Lima se indicó que “(...) si bien las instancias inferiores concluyen en la precariedad de los demandados, tomando en consideración que ha operado la cláusula resolutoria pactada en el contrato de promesa de compraventa, invocando para ello lo dispuesto en el artículo 1430 del Código Civil, sin embargo, no toman en cuenta, que dicha titularidad es respecto solo del terreno, habiendo los demandados alegado tener derechos de propiedad respecto a la vivienda construida sobre el lote en referencia".

(3) Específicamente, en el cuarto considerando de la Casación No. 3780-2000-Callao se manifestó lo siguiente: "Que, en este proceso sumarísimo no puede dilucidarse tal discrepancia y determinar si en realidad ha quedado resuelto el contrato tal como afirma la demandante o no procede la resolución del mismo como lo han sostenido los demandados, por lo que se tendría que recurrir a una vía más lata".

(4) Por un lado, en el cuarto considerando de la Casación No. 2540-1999-Lima se sustentó el siguiente criterio: "Que, la precariedad en el uso de los bienes inmuebles, no se determina únicamente por la carencia de un título de propiedad o arrendatario, debe entenderse como tal, la ausencia absoluta de cualquier circunstancia que permita advertir la legitimidad de la posesión que ostenta el ocupante obviamente en armonía con el orden público y las buenas costumbres; por lo que siendo esto así, es evidente que existe errónea interpretación del artículo 1708 del Código Sustantivo y por ende del artículo 911 del mismo Cuerpo Legal, lo que ha dado lugar para que la Sala Civil revocando la apelada declare Fundada la demanda, atribuyéndole al demandado una condición jurídica que no tiene".

(5) De otro lado, en el octavo considerando de la Casación No. 1875-2008-Cañete se señaló literalmente que: "(...) la esencia del artículo 1708 radica en establecer que el nuevo propietario no tiene obligación de respetar el contrato de arrendamiento celebrado con anterioridad a su adquisición si el mismo no se encuentra inscrito, recogiéndose así el principio romano emptio tollit locatum (la venta rompe el arrendamiento), lo que se justifica porque el propietario desde que adquiere la posición jurídica tiene derecho a servirse -prima facie- del bien ejerciendo los atributos que otorga la propiedad expresados en el artículo 923 del Código Civil, en tanto que el arrendatario al mantener una relación jurídica no oponible a aquel no puede privarlo del ejercicio de tales atributos". 


\section{Luis Felipe Del Risco}

indeterminado y que tenía que devolverlo a su propietario apenas este así se lo exigiera(6).

Otra postura sostiene que el precario del Código Civil es un tipo de posesión ilegítima (artículo 906 del Código Civil), pues considera que no existe mayor distinción entre ambas categorías en tanto los efectos de la posesión sin título (precaria) y la posesión afectada por un vicio (ilegítima) son muy similares: el poseedor no tiene derecho a la posesión del bien ${ }^{(7)}$.

Asimismo, hay quienes consideran que el precario es una categoría procesal que solo puede analizarse dentro de un proceso de desalojo y que la legitimidad o ilegitimidad de la posesión debe verse en un plano distinto. Según esta postura, el proceso de desalojo consiste solamente en un pre-examen sobre quién tiene el derecho, por lo cual lo que se decida allí no afecta en nada lo que se pueda ver en otro proceso más largo (Mejorada 2006).

Otro sector de la doctrina parte de una interpretación contrario sensu del artículo 911 del Código Civil y determina que, a diferencia del precario, el poseedor ilegítimo sí cuenta con un título, aun cuando este es inválido. En atención a esta distinción, se concluye que no es lo mismo posesión precaria que posesión ilegítima (Torres 2005).

Como se puede apreciar, antes del Cuarto Pleno Casatorio existían distintas posturas sobre el proceso de desalojo por ocupación precaria. La configuración del precario era discutida tanto a nivel jurisprudencial como en doctrina. Pero además existían cuestionables decisiones judiciales que cercenaban indebidamente el alcance del desalojo como instrumento de tutela urgente. Es por ello que el Cuarto Pleno Casatorio, con el propósito de uniformizar criterios y de generar predictibilidad en el sistema, elaboró siete reglas que constituyen precedente vinculante, las cuales serán analizadas en el siguiente acápite.

\section{El Cuarto Pleno Casatorio Civil}

El Cuarto Pleno Casatorio Civil estableció siete reglas vinculantes que a continuación describiremos, analizaremos y sobre las cuales daremos nuestro punto de vista.

La primera regla señala lo siguiente:

"Una persona tendrá la condición de precaria cuando ocupe un inmueble ajeno, sin pago de renta y sin título para ello, o cuando dicho título no genere ningún efecto de protección para quien lo ostente, frente al reclamante, por haberse extinguido el mismo" (énfasis agregado).

En esta primera regla se define al precario. Se manifiesta que un poseedor precario será aquel que ocupe un inmueble ajeno, sin pagar renta y sin título para ello. En términos generales, esta definición va acorde con la prevista en el Código Civil. Sin embargo, consideramos que el hecho de pagar o no la renta no es una característica esencial del concepto de precario.

Y es que no siempre se cumplirá el supuesto de falta de pago de renta. Puede existir pago y precariedad al mismo tiempo. Es el caso de un arrendatario que tiene un título vencido, pero continúa pagando renta en la cuenta bancaria consignada en el contrato de arrendamiento, a pesar de que el arrendador le ha requerido la restitución del bien. No por este hecho (pago de renta) deja de configurarse la condición de precario, salvo que el arrendador haya renunciado a su pedido de restitución a través

(6) Al respecto, véase Gunther Gonzales Barrón, Derechos Reales (Lima: Ediciones Legales, 2009), 176-7.

(7) Sobre el particular, véase Jorge Avendaño Valdez, "Las modificaciones del Libro de los Derechos Reales," en Instituto de Investigación Jurídico Notarial. Reforma del Código Civil Peruano. Doctrina y Propuestas (Lima: Gaceta Jurídica, 1988), 201. 


\section{El desalojo por ocupación precaria a la luz del Cuarto Pleno Casatorio Civil The eviction due to precarious occupation in the light of the Fourth Civil Cassation Plenaries}

de la aceptación de los pagos. Lo cierto es que el asunto debe ser analizado caso por caso. Para tal efecto, lo esencial no es el pago de la renta por parte del ocupante, sino que haya ausencia de título o que, habiéndolo, este se haya extinguido. Es decir, que se presenten cualquiera de los dos supuestos previstos en el artículo 911 del Código Civil.

A nuestro parecer es una obviedad la referencia a que el precario ocupe un inmueble ajeno. Si fuese un inmueble propio tendría título para poseer (propiedad). Creemos innecesaria esta referencia. Basta la formulación genérica de la ausencia de título o su extinción para concebir al precario. Siempre se producirá en un inmueble de propiedad de un tercero.

Por otro lado, el supuesto de considerar como precario al que tiene un título, "pero que no genera ningún efecto de protección para quien lo ostente" (por haberse extinguido) es adecuado, porque ese supuesto se refiere al que tiene formalmente un título, pero este ha fenecido. Se sigue la orientación contenida en el artículo 911 del Código Civil.

La Corte Suprema estableció como segunda regla la siguiente:

"Cuando se hace alusión a la carencia de título o al fenecimiento del mismo, no se está refiriendo al documento que haga alusión exclusiva al título de propiedad, sino a cualquier acto jurídico que le autorice a la parte demandada a ejercer la posesión del bien, puesto que el derecho en disputa no será la propiedad sino el derecho a poseer" (énfasis agregado).

Esta regla es muy importante y marca el espectro de protección del proceso de desalojo. Acá no está en juego la propiedad (no se tiene que acreditar ser dueño del bien para acceder a la parte activa de este juicio) y es un error entender el Cuarto Pleno Casatorio como un precedente vinculante acerca del dominio y sus mecanismos de protección. No existe aquí necesariamente una rivalidad que vincule a un propietario no poseedor contra un poseedor no propietario (como sí ocurre en materia de acción reivindicatoria - artículo 927 del Código Civil(8)), sino lo que está en discusión es quién tiene mejor derecho a poseer. Se analizará entonces el título que habilita a la posesión en cada una de las posiciones encontradas (demandante y demandado) y en función de ello se resolverá la controversia.

Por la razón anterior es que el proceso de desalojo está al alcance del arrendatario, usufructuario o de cualquier poseedor inmediato del bien (artículo 905 del Código Civil). No debe asociarse exclusivamente con el derecho de propiedad.

La tercera regla establecida por el Cuarto Pleno Casatorio es la siguiente:

"Interpretar el artículo 585 del Código Procesal Civil en el sentido de que por 'restitución' del bien se debe entender como entrega de la posesión que protege el artículo 911 del Código Civil, para garantizar al sujeto a quien corresponde dicho derecho a ejercer el pleno disfrute del mismo, independientemente de que es propietario o no" (énfasis agregado).

El primer párrafo del artículo 585 del Código Procesal Civil establece que "la restitución de un predio se tramita con arreglo a lo dispuesto para el proceso sumarísimo y las precisiones indicadas en este subcapítulo".

Antes del Cuarto Pleno Casatorio existían ocupantes que sostenían que nadie les había entregado o cedido la posesión del bien, por lo que no tenían un deber de restitución a su cargo. Se trataban de posesiones directas o derivadas de un tercero distinto al titular demandante. Bajo esta perspectiva, no se tenía en estricto obligación contractual de devolver, toda vez que el demandante no les había entregado la posesión del bien. Con este argumento, los demandados impedían que se les ordene restituir el bien que estaban ocupando.

(8) El artículo 927 del Código Civil dispone lo siguiente: "La acción reivindicatoria es imprescriptible. No procede contra aquel que adquirió el bien por prescripción". 


\section{Luis Felipe Del Risco}

El Cuarto Pleno Casatorio zanja esta defensa exageradamente formal y establece que la restitución a la que se refiere el artículo 585 del Código Procesal Civil debe entenderse, para efectos del proceso de desalojo, como un pedido genérico de entrega de la posesión que le corresponde, como es natural, al titular del derecho a poseer. Nótese que no es necesario que exista un vínculo previo entre el demandante y el demandado para que nazca este deber de restitución, el cual no tiene un origen convencional, sino que es esencialmente legal.

La cuarta regla es la que sigue:

"Establecer conforme el artículo 586 del Código Procesal Civil, que el sujeto que goza de legitimación para obrar activa no solo puede ser el propietario, sino también el administrador y todo aquel que considere tener derecho a la restitución de un predio. Por otra parte, en lo que atañe a la legitimación para obrar pasiva se debe comprender dentro de esa situación a todo aquel que ocupa el bien sin acreditar su derecho a permanecer en el disfrute de la posesión, porque nunca lo tuvo o el que tenía feneció".

El artículo 586 del Código Procesal Civil estipula lo siguiente:

"Pueden demandar: el propietario, el arrendador, el administrador y todo aquel que, salvo lo dispuesto en el artículo 598, considere tener derecho a la restitución de un predio.

Pueden ser demandados: el arrendatario, el subarrendatario, el precario o cualquier otra persona a quien le es exigible la restitución".

La cuarta regla del precedente permite identificar con claridad quiénes son los sujetos que cuentan con legitimidad en el proceso de desalojo. Nuevamente se identifica las dos posiciones que deben ser evaluadas por los jueces: el demandante, quien debe probar tener un título que le permita poseer el bien que no ocupa (todo aquel que ostente un derecho a la restitución del predio - derecho a la posesión); y el demandado, quien debe acreditar que su posesión actual está amparada en un título vigente (debe acreditar que no hay ausencia de título o que su título no ha fenecido).
La quinta regla del Cuarto Pleno Casatorio contiene una enunciación de ciertas situaciones comunes de precariedad. Formula casos que han sido conocidos por la judicatura y da pautas para su solución, sin establecer una lista taxativa de los supuestos de precariedad. Estos son los siguientes:

a) Cuando el ocupante es parte de un contrato que ha quedado resuelto extrajudicialmente (artículos 1429 y 1430 del Código Civil), siempre que para la resolución se haya cumplido con el procedimiento formal previsto en la ley y en el mismo contrato. En este caso, el título fenece (pierde eficacia conforme al artículo 1371 del Código Civil( ${ }^{(9)}$ ) y, por ende, el ocupante tiene la condición de precario. Puede ser el caso, por ejemplo, de la resolución de un contrato de compraventa a plazos. Ante el incumplimiento del contrato y posterior resolución, el comprador ocupante se convierte en precario para efectos de la ley.

Adviértase que en estos casos el juez no debe pronunciarse sobre la resolución contractual ni respecto de las condiciones que ameritaron el ejercicio de dicha tutela. Solo debe evaluar los hechos y determinar quién tiene mejor derecho a poseer, según las circunstancias que hayan sido probadas por las partes. Es un pre examen de la situación que no impide que la discusión sobre la resolución contractual se presente en otro proceso. Si los argumentos y pruebas aportados por el demandante no le generan convicción, el juez puede resolver declarando la infundabilidad de la demanda. No debe optar por su improcedencia.

b) Cuando el poseedor tiene un contrato de arrendamiento ya vencido con el

(9) El artículo 1371 del Código Civil establece lo siguiente: "La resolución deja sin efecto un contrato válido por causal sobreviniente a su celebración". 


\section{El desalojo por ocupación precaria a la luz del Cuarto Pleno Casatorio Civil The eviction due to precarious occupation in the light of the Fourth Civil Cassation Plenaries}

propietario y este ha expresado su voluntad indubitable de concluir la relación exigiendo la devolución del bien, de conformidad con los artículos 1700 y 1704 del Código Civil(10). Se precisa que el solo vencimiento del contrato no convierte al arrendatario en precario, sino que para verificarse dicha condición es necesario el requerimiento del arrendador, de lo contrario se entenderá la continuación del alquiler hasta que ello no suceda.

c) Cuando el título del poseedor esté inmerso en una causal de invalidez absoluta y esta sea evidente, conforme a los artículos 219 y 220 del Código Civil. Es el caso, por ejemplo, que durante el trámite del proceso de desalojo el juez advierte que el título posesorio adolece de simulación absoluta o hubiera sido practicado por persona absolutamente incapaz.

El Cuarto Pleno Casatorio establece que el juez no puede aquí declarar la nulidad del acto jurídico, sino considerará esta circunstancia para efectos de declarar fundada o infundada la demanda de desalojo, analizando la nulidad en la parte considerativa de la sentencia. Esta regla ha sido modificada por el Noveno Pleno Casatorio, el cual señala lo siguiente:

"8. Se modifica el precedente vinculante contenido en el punto 5.3. del Cuarto Pleno Casatorio Civil (Casación No. 2195-2011-Ucayali) de fecha trece de agosto de dos mil doce, debiéndose entender en lo sucesivo que: $\mathrm{Si}$ en el trámite de un proceso de desalojo, el Juez advierte la invalidez absoluta y evidente del título posesorio, conforme lo prevé el artículo 220 del Código Civil, previa promoción del contradictorio entre las partes, declarará dicha situación en la parte resolutiva de la sentencia $y$, adicionalmente, declarará fundada o infundada la demanda de desalojo, dependiendo de cuál de los títulos presentados por las partes es el que adolece de nulidad manifiesta".

d) Cuando el ocupante posee un bien en virtud de un contrato de arrendamiento no inscrito y se produce la venta del predio. Frente al nuevo dueño el poseedor se transforma en precario (no tiene un título emitido por el titular actual del bien que justifique su presencia en el predio; se trata de un supuesto de ausencia de título), salvo aquel se comprometa a respetar el arrendamiento pactado entre el antiguo propietario y el arrendatario, conforme lo establece el artículo 1708 del Código Civil ${ }^{(11)}$.

e) Cuando el poseedor alega haber realizado edificaciones o modificaciones sobre el

(10) Los artículos 1700 y 1704 del Código Civil señalan lo siguiente:

"Artículo 1700.-

Vencido el plazo del contrato, si el arrendatario permanece en el uso del bien arrendado, no se entiende que hay renovación tácita, sino la continuación del arrendamiento, bajo sus mismas estipulaciones, hasta que el arrendador solicite su devolución, la cual puede pedir en cualquier momento".

"Artículo 1704.-

Vencido el plazo del contrato o cursado el aviso de conclusión del arrendamiento, si el arrendatario no restituye el bien, el arrendador tiene derecho a exigir su devolución y a cobrar la penalidad convenida o, en su defecto, una prestación igual a la renta del período precedente, hasta su devolución efectiva. El cobro de cualquiera de ellas no importará la continuación del arrendamiento".

(11) El artículo 1708 del Código Civil dispone lo siguiente:

"En caso de enajenación del bien arrendado se procederá del siguiente modo:

Si el arrendamiento estuviese inscrito, el adquirente deberá respetar el contrato, quedando sustituido desde el momento de su adquisición en todos los derechos y obligaciones del arrendador.

Si el arrendamiento no ha sido inscrito, el adquirente puede darlo por concluido.

Excepcionalmente, el adquirente está obligado a respetar el arrendamiento, si asumió dicha obligación.

Tratándose de bienes muebles, el adquirente no está obligado a respetar el contrato si recibió su posesión de buena fe". 


\section{Luis Felipe Del Risco}

predio materia de desalojo, ya sean estas ejecutadas de buena o mala fe. El Cuarto Pleno Casatorio señala con acierto que en este caso lo único que debe ser evaluado por el juez es el derecho a poseer del demandante, puesto que las obras ejecutadas por el ocupante y la consecuencia legal de su edificación en el predio deben ser evaluadas en otro proceso a la luz de los artículos 941, 942 y 943 del Código Civil(12). Con ello se deja por sentado que la presencia de obras no son un obstáculo legal para evaluar el desalojo ${ }^{(13)}$, el cual debe proceder con prescindencia de las edificaciones.

f) Cuando el poseedor alega haber ganado el derecho de propiedad por prescripción adquisitiva (artículo 950 del Código Civil(14)), pero no exhibe prueba que acredite este hecho jurídico. Así, la mera alegación de prescripción no es suficiente para desestimar la pretensión de desalojo o para declarar su improcedente. El juez nuevamente aquí tiene que realizar un pre examen de la situación puesta a su conocimiento, sin que ello implique que declare o niegue la usucapión.

Los supuestos descritos fueron desarrollados por el Cuarto Pleno Casatorio porque eran los más frecuentes en la jurisprudencia peruana. Reiteramos: se trata de una lista enunciativa y no taxativa, por lo cual pueden presentarse muchos más supuestos de precariedad, los cuales deben ser desentrañados en función de los elementos básicos de esta figura legal (primera regla) $^{(15)}$.

Se han formulado diversas críticas contra los supuestos de precariedad establecidos por la Corte Suprema. Así, por ejemplo, en el caso del quinto supuesto, referido a la usucapión, Gonzales Barrón manifiesta que no existe una tutela igualitaria para las partes debido a que si bien al demandado en un proceso de desalojo se le da un plazo para que pueda responder la demanda, este tiempo sería demasiado corto. Se trata de solo cinco (5) días, lo que implica que no haya tiempo suficiente para poder juntar los medios probatorios que se van a presentar y, con ello, aumentan las posibilidades de que se ordene ir a un proceso posterior a la hora de discutir sobre la prescripción adquisitiva (Gonzales).

Por su parte, Ramírez Cruz señala que la prescripción adquisitiva debe entenderse como acción y no como excepción. Por lo tanto, según su postura, si es que hubiera

(12) Los artículos 941, 942 y 943 del Código Civil señalan lo siguiente:

"Artículo 941.- Cuando se edifique de buena fe en terreno ajeno, el dueño del suelo puede optar entre hacer suyo lo edificado u obligar al invasor a que le pague el terreno. En el primer caso, el dueño del suelo debe pagar el valor de la edificación, cuyo monto será el promedio entre el costo y el valor actual de la obra. En el segundo caso, el invasor debe pagar el valor comercial actual del terreno".

"Artículo 942.- Si el propietario del suelo obra de mala fe, la opción de que trata el artículo 941 corresponde al invasor de buena fe, quien en tal caso puede exigir que se le pague el valor actual de la edificación o pagar el valor comercial actual del terreno".

"Artículo 943.- Cuando se edifique de mala fe en terreno ajeno, el dueño puede exigir la demolición de lo edificado si le causare perjuicio, más el pago de la indemnización correspondiente o hacer suyo lo edificado sin obligación de pagar su valor. En el primer caso, la demolición es de cargo del invasor".

(13) Por lo demás, debe tenerse en cuenta que en éste caso no debería existir discusión sobre la titularidad de las obras. Todas pertenecen al dueño del suelo, según el principio de accesión inmobiliaria previsto en el artículo $938^{\circ}$ del Código Civil.

(14) El artículo 950 del Código Civil indica que "la propiedad inmueble se adquiere por prescripción mediante la posesión continua, pacífica y pública como propietario durante diez años. Se adquiere a los cinco años cuando median justo título y buena fe".

(15) La Corte Suprema ha tenido la oportunidad de tratar otros casos asociados a la precariedad, donde el origen del título del demandado está basado en vínculos de parentesco (Casación No. 2945-2013-Lima), afincado en relaciones sucesorias (Casaciones No. 4291-2011-Tacna y No. 2652-2005-Lima Norte) o provenientes de las consecuencias patrimoniales de la unión de hecho (Casación No. 3191-2010). Como se puede apreciar, los supuestos de precariedad son múltiples, ya que debe examinarse caso por caso si es que hay ausencia de título o este ha fenecido. 


\section{El desalojo por ocupación precaria a la luz del Cuarto Pleno Casatorio Civil The eviction due to precarious occupation in the light of the Fourth Civil Cassation Plenaries}

una demanda de desalojo contra alguien que ha adquirido la propiedad por prescripción adquisitiva, debería de suspenderse la demanda de desalojo e iniciarse un proceso de prescripción adquisitiva (Ramírez 2013).

Por otro lado, existen también críticas con respecto al segundo supuesto de posesión precaria relacionado con el vencimiento del contrato de arrendamiento y el pedido de restitución que convierte al ocupante en precario. Abanto Torres manifiesta que este supuesto debería ser considerado como uno de vencimiento del plazo del contrato, no como un proceso de desalojo por precario (Abanto 2013). La consecuencia práctica de la referida distinción es que el proceso iniciaría en un Juzgado de Paz Letrado y concluiría en un Juzgado Especializado o Mixto. En cambio, si se tramita como un proceso de desalojo, se inicia en un Juzgado Especializado o Mixto, teniendo como segunda instancia la Corte Superior y pudiendo llegar mediante recurso de casación hasta la Corte Suprema. Ello implica que el proceso sea más largo, cuando lo que supuestamente se busca es que haya una tutela rápida.

Más allá de las críticas que se le pueda formular al listado formulado en el Cuarto Pleno Casatorio, este sin duda promueve la legítima aspiración de que toda demanda de desalojo por ocupación precaria tenga un pronunciamiento sobre la posesión y trata de evitar a toda costa que el proceso quede descartado a través de la declaración de improcedencia de la demanda.

Al establecer los supuestos de precariedad, la Corte Suprema ha buscado evitar que los precarios se aprovechen indebidamente del sistema para retrasar u obstaculizar el desalojo. El objetivo, en definitiva, está dirigido a generar una tutela rápida para todo aquel que tenga derecho a la posesión. Nótese que ello no implica que se deje sin protección a aquel que adquirió la propiedad por prescripción adquisitiva, por ejemplo, sino que se concluye que, en estos casos, la discusión respecto al derecho de propiedad podrá ser resuelta en un proceso posterior. Del mismo modo ocurrirá en los demás casos. No hay indefensión, sino una tutela anticipada en razón de la urgencia de los intereses en juego. Se prefiere pues darle la posesión del bien a quien tiene derecho a él, dejando que las materias más complejas sean analizadas en juicios de mayor duración y trámite.

Siguiendo con el análisis del Cuarto Pleno Casatorio, la sexta regla establece lo siguiente:

\begin{abstract}
"En todos los casos descritos, el juez del proceso no podrá expedir una sentencia inhibitoria, sino que deberá pronunciarse sobre el fondo de la materia controvertida, en el sentido de que corresponda, conforme a los hechos y la valoración de las pruebas aportadas".
\end{abstract}

Esta sexta regla nos permite observar el criterio que sirvió de base para el pronunciamiento de los magistrados. La finalidad del pleno es clara y está orientado a brindar una protección eficaz al derecho a la posesión y a que los jueces, en todos los casos, se pronuncien sobre esta titularidad, que es lo que realmente debe ocurrir en el proceso de desalojo. Existe ahora una prohibición a la inhibición que esperemos se produzca en la práctica judicial. Todos los jueces deben pronunciarse sobre el fondo del asunto controvertido, en función de la información y pruebas aportadas al proceso.

Finalmente, la séptima y última regla del Cuarto Pleno Casatorio es la siguiente:

"En lo que concierne a lo dispuesto por el artículo 601 del Código Procesal Civil, cuando ya ha prescrito el plazo para interponer la pretensión interdictal, el accionante no podrá optar por recurrir al desalojo para lograr la recuperación del bien".

Esta regla se ha recogido en el Cuarto Pleno Casatorio sin mayor desarrollo que la justifique.

Traslada el plazo de prescripción extintiva de la acción interdictal, dirigida a cautelar el derecho de posesión (posesión efectiva, entendida como un hecho que se transforma en un derecho), al proceso de desalojo, que procura defender el derecho a la posesión (derivado de un título habilitante que genera el derecho a ejercer y reclamar la posesión de determinado bien). 


\section{Luis Felipe Del Risco}

A nuestro parecer, este punto es de dudosa legalidad, pues solo la ley puede fijar los plazos de prescripción en nuestro ordenamiento jurídico (artículo 2000 del Código Civil(16)), y no hay ningún dispositivo normativo que vincule la prescripción de la acción interdictal con el plazo para demandar el desalojo.

\section{Comentario final}

Sin perjuicio de que la materia está lejos de agotarse con el planteamiento realizado en el Cuarto Pleno Casatorio, la finalidad que persigue nos parece loable: brindar predectibilidad y seguridad jurídica en nuestro sistema con relación a las ocupaciones ilegítimas.

Debemos ser conscientes que es un primer paso y hay mucho camino por recorrer. No solo debemos ser celosos guardianes de su correcta aplicación, sino que el pleno debe estar acompañado de otras medidas que permitan que el desalojo sea una verdadera herramienta de protección para los derechos posesorios. La justicia para estos casos no puede tardar años y debe generarse un incentivo económico que disuada que las posesiones precarias se perpetúen y expandan en nuestro país.

\section{Referencias Bibliográficas}

Abanto Torres, Jaime. 2013. Análisis del precedente vinculante establecido por el Cuarto Pleno Casatorio Civil. Gaceta Civil y Procesal Civil - Especial Cuarto Pleno Casatorio Civil 3 (setiembre).

Gonzales Barrón, Gunther. Comentario breve al decepcionante Cuarto Pleno Civil. Gaceta Jurídica - Actualidad Civil y Registral 243 (febrero).

Mejorada Chauca, Martín. 2006. Precario ¿y qué? Gaceta Jurídica - Actualidad Jurídica 151 (junio): 60.

Ramírez Cruz, Eugenio. 2013. La posesión precaria en la visión del Cuarto Pleno Casatorio Civil: Doctrina versus jurisprudencia. Gaceta Civil y Procesal Civil - Especial Cuarto Pleno Casatorio Civil 3 (setiembre).

Torres Vásquez, Aníbal. 2005. ¿En qué consiste la posesión precaria? Gaceta Jurídica - Actualidad Jurídica 139 (abril): 91.

(16) El artículo 2000 del Código Civil señala expresamente lo siguiente: "Solo la ley puede fijar los plazos de prescripción". 